\title{
STUDY OF TEC VARIATIONS USING PERMANENT STATIONS GNSS DATA IN RELATION WITH SEISMIC EVENTS. APPLICATION ON SAMOTHRACE EARTHQUAKE OF 24 MAY 2014
}

\author{
Christos PIKRIDAS, Stylianos BITHARIS®*, Symeon KATSOUGIANNOPOULOS, \\ Kyriaki SPANAKAKI, Ion-Anastasios KAROLOS \\ Department of Geodesy and Surveying, Aristotle University of Thessaloniki, Thessaloniki, Greece
}

Received 25 April 2019; accepted 22 November 2019

\begin{abstract}
This study investigates the ionospheric total electron content (TEC) variations prior to the earthquake (MW = 6.9) of 24 May 2014 in Samothraki island of north Aegean Sea in Greece. TEC estimates were analyzed using data from GNSS (GPS+Glonass) permanent networks with the aim to detect possible ionospheric anomalies associate with the seismic event. The test period covers one week of data, 4 days before and two days after the event. Selected GNSS stations are scattered around seismic epicenter of distances from 16 up to $1375 \mathrm{~km}$. TEC values estimated for every hour using PPP technique with Bernese GPS software. A comparison with global TEC estimates derived from CODE and JPL institute confirms the validation of results. It is found that a significant decrease 1-day prior to earthquake occurs at all of the selected stations. This result is not obvious when standard ionospheric model is performed for the estimation of TEC. Therefore, in such cases the use of dedicated GNSS processing data scenario is mandatory. A spatial analysis on TEC estimates with geometrical properties shows that the 1-day decrement is related with the EQ shock and may point the location area of the Earthquake. Finally, we conclude that the lithosphere-atmosphere-ionosphere coupling (LAIC) mechanism through acoustic or gravity waves has a key role for this phenomenology.
\end{abstract}

Keywords: GNSS data, total electron content, Earthquake shock.

\section{Introduction}

It is well known that the ionosphere has a significant contribution in the propagation of electromagnetic radio waves. Signal propagations are widely affected due to large variability in the ionosphere. The study of ionospheric disturbances during seismic activities has become an interesting field through the so-called lithosphere-atmosphere-ionosphere mechanism (Molchanov et al., 2004, 2005; Koperanov, Hayakawa, Yampolski, \& Lizunov, 2008). This complex mechanism produces electromagnetic waves which leads to changes of ionosphere, through the penetration in its lower layers and causes anomalies in ionospheric parameters (Pulinets, Legen, Gaivoronskaya, \& Depuev, 2003). Although the seismogenic mechanisms are not fully understood, it is assumed that these anomalies first appear near Earth's surface and then emitted to higher altitudes. The wave like perturbations in the ionosphere are generally referred to as traveling ionospheric disturbances (TIDs) and are manifestations of acoustic/atmospheric gravity waves which are excited in the lower atmosphere and propagate upwards. Therefore, a lot of case studies have been done by a large number of researchers concerning the influence of earthquakes on ionospheric parameters (for example, Calais \& Minster, 1998; O. P. Singh, Chauhan, V. Singh, \& B. Singh, 2009; Astafyeva \& Heki, 2011). One way of monitoring the ionospheric variability and more specific the TEC (Total Electron Content) values is through the analysis of permanent GNSS station data (Wild, 1994; Schaer, 1999; Pikridas \& Chatzinikos, 2007). Currently, thousands of GNSS receivers are used to monitor the Earth's crust deformations. While observing Earth's surface deformation and provide their data for positioning services, a network of GNSS receivers can be employed to monitor the ionospheric total electron content. TEC values retrieved from GNSS data have made a considerable contribution to the understanding of seismo-ionospheric variations (for example, Calais \& Minster, 1998; Liu et al., 2004; Pulinets \& Boyarchuk,

${ }^{*}$ Corresponding author. E-mail: smpithar@topo.auth.gr 
2004; Contadakis, Arabelos, Asteriadis, Spatalas, \& Pikridas, 2008, 2012; Sharma et al., 2010; Yao, Chen, Wu, Zhang, \& Peng, 2012).

In this paper, the TEC values of 24 permanent stations, most of them scattered in Greek area and close to the earthquake epicenter, were estimated for investigation of any relationship between the variations which may occur over an area before and during a seismic event. The processing scenario was applied using the Precise Point Positioning (PPP) algorithm with the help of Bernese software v5.2. As a consequence, the derived TEC values were analyzed using computational techniques taking into account the basic parameters that stations located from 16 to almost $1400 \mathrm{Km}$ away from the earthquake (epicenter) that occurred on the 24th of May 2014 at NE Greece and most of them within the preparation zone. In addition, the effectiveness of new empirical ionospheric models while the use of global ionospheric products like IONEX files were also examined if can be employed to detect seismoionospheric signatures and for validation purposes.

\section{The northern Aegean seismic activity and the strong earthquake of May 2014}

The recent evolution of the northern Aegean is characterized by the westward motion of the Anatolian plate along the North Anatolian Fault (e.g. Jolivet, 2011) which in turn pushes the Aegean plate southwards (Papazachos,
Kiratzi, \& Kontopoulou, 1998; Pavlides et al., 2010). The main active tectonic structures in the study area can be found in the Greek Database of Seismogenic Sources GreDaSS which done by a group of researchers (Caputo, Chatzipetros, Pavlides, \& Sboras, 2013). As a consequence, Greek region is characterized as the most geodynamical area in Europe.

A strong earthquake struck off the coast of northern Greece on Saturday 24th May (DOY 144), at 09:25 (UTC) and was felt as far away as neighboring Turkey and Bulgaria but there were no reports of serious casualties or destruction. The earthquake occurred about $77 \mathrm{~km}$ (48 miles) south-southwest of Alexandroupolis, between the islands of Lemnos and Samothraki, at a depth of $12 \mathrm{~km}$ (7 miles) (Sboras et al., 2015). The magnitude varies from Mw 6.2 (AUTh) up to MW6.9, which was suggested by the majority of institutes. Figure 1 displays the main shock and aftershocks which occurred within the day (24th May) as provided by relevant webpage of the Department of Geophysics of AUTh (http://geophysics.geo.auth.gr).

\section{TEC values estimation using GNSS data}

For the process of GNSS data two well-known techniques are applied. The first, is known as the "Point positioning" and the second one as the "Relative positioning". Both techniques are estimating the coordinates of a GNSS receiver deployment at a site. Relative positioning is highly

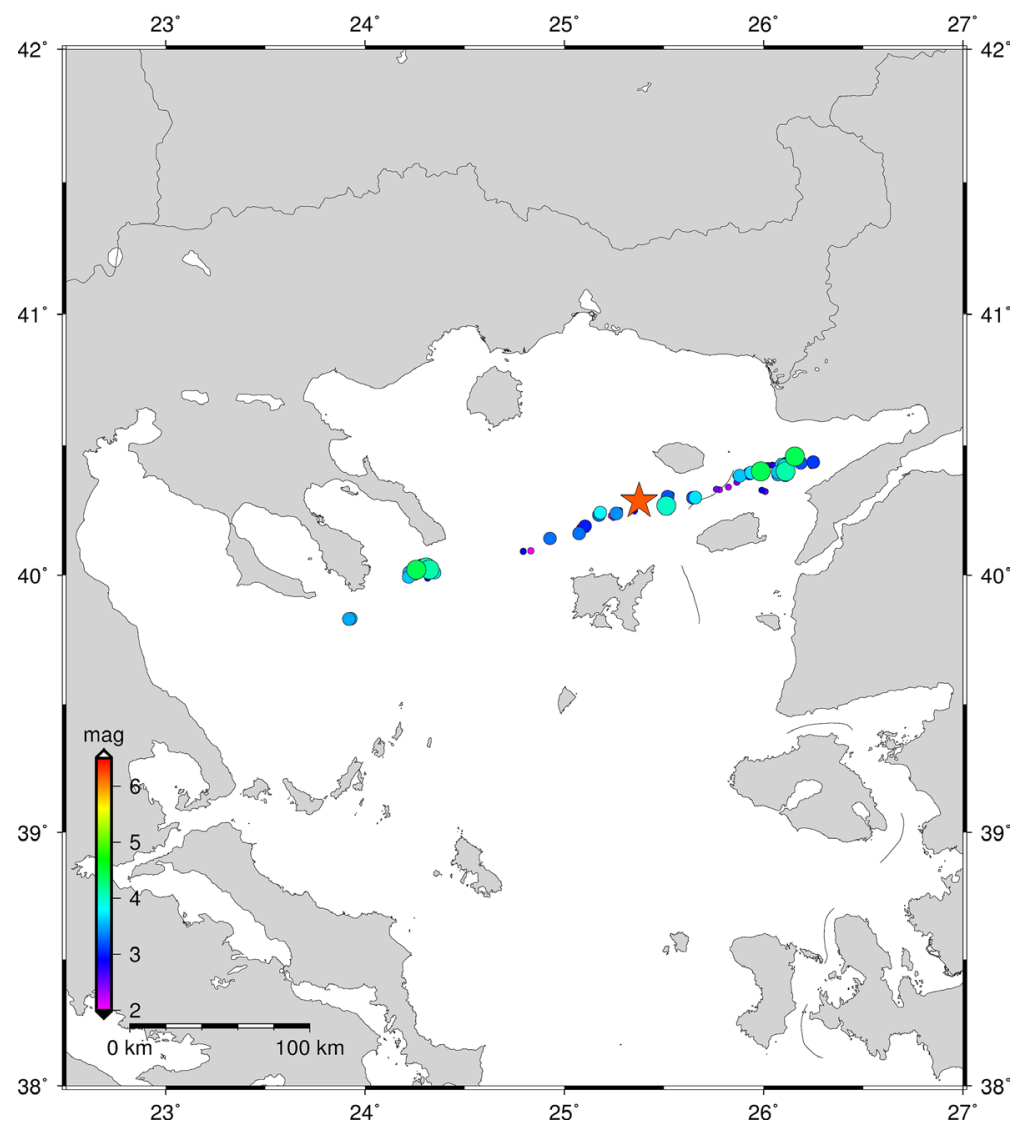

Figure 1. Earthquake activity in 24 May 2014 between islands Lemnos and Samothraki NE of Greece 
accurate, and commonly used in Earth sciences (Bitharis et al., 2016). A type of a standalone point positioning techniques available in post process is the Precise Point Positioning (PPP). PPP uses zero-difference pseudoranges and carrier phase data utilizing precise orbits, clock values (retrieving from analysis centers) and models for account of satellite antenna offset and earth and ocean tide loading. This algorithm can potentially achieve centimeter- and decimeter-level accuracy in static and kinematic modes, respectively, depending on the number and geometry of visible GPS satellites, and quality of observations. More specific, PPP provides decimeter $(10 \mathrm{~cm})$ positioning accuracy and sub-nanosecond time transfer accuracy anywhere in the world, independent of local infrastructure. For a data files spanning 24 hours the positioning accuracy can be less than $5 \mathrm{~cm}$. This technique can be considering as equivalent with network solution for ionospheric (TEC) studies. This is done in the present study because daily station data were processed. It is worth to be mentioned that most of the permanent stations records GPS and GLONASS data which is an advance for the impact of Satellite geometry in the process. In addition, the combination of GPS and GLONASS data are a perfect opportunity for TEC variations research.

In this study, the Bernese v5.2 GNSS software was used. Referring to the basic information for data processing parameters, the dedicated BPE process control file (PCF) for estimating station-specific ionosphere models was selected (Dach \& Walser, 2015). This includes that the GNSS data was analyzed with a satellite elevation cut-off angle of 10 degrees, final precise orbit information was used from IGS directory (available after 12 days) which refers to the IGb08 reference frame and the new IGS_08.atx model with absolute antenna calibration values was applied. For the account of the tropospheric refraction, the Saastamoinen model (Saastamoinen, 1972) with VMF1 mapping function was used (Boehm, Werl \& Schuh, 2006). The GNSS TEC values were estimated by assuming the ionospheric shell at fixed height of $450 \mathrm{~km}$ above the Earth's surface. Also, the relevant Differential Code Biases (DCB) file for all satellites was retrieved from the AIUB Data Center of the University of Bern at Switzerland.

The (hourly) TEC estimates were extracted for all stations and for a time period of 7 days starting from 20/5/2014 until to 26/5/2014 (DOY from 140 to 146). The Greek Continuously Operated Reference Stations (CORS) are part of three permanent GNNS networks like, SmartNet, HermesNet and HEPOS as shown in Figure 3. The other stations are part of EPN/EUREF and IGS networks. These stations have an area size of about $1700 \mathrm{~km}$ in latitude and $2600 \mathrm{~km}$ in longitude. Figure 2 displays the geographical distribution of all the selected permanent GNSS stations (red bullets) while Table 1 presents the station names, geographic coordinates and their distances from the earthquake epicenter.

Figure 3 shows the geographical distribution of the Greek permanent stations (with red bullets) and the
Table 1. Geographic coordinates and distances from EQ epicenter of the selected GNSS stations

\begin{tabular}{|c|c|c|c|}
\hline Station name & Latitude & Longitude & $\begin{array}{c}\text { Distance from } \\
\text { epicenter }(\mathrm{km})\end{array}$ \\
\hline $018 B$ & 40.47 & 25.52 & 16 \\
\hline LEMN & 39.53 & 25.1 & 60 \\
\hline ALEX & 40.5 & 25.51 & 70 \\
\hline KOMO & 41.07 & 25.24 & 87 \\
\hline KAVA & 40.56 & 24.23 & 123 \\
\hline PRKV & 39.14 & 26.15 & 134 \\
\hline ORES & 41.24 & 26.32 & 141 \\
\hline STRA & 40.31 & 23.47 & 156 \\
\hline AUT1 & 40.38 & 16.42 & 220 \\
\hline CHIO & 38.22 & 26.07 & 224 \\
\hline ISTA & 41.06 & 29.01 & 300 \\
\hline SOFI & 42.33 & 23.23 & 307 \\
\hline TUBI & 40.47 & 29.27 & 330 \\
\hline ORID & 41.07 & 20.47 & 416 \\
\hline BUCU & 44.27 & 26.07 & 458 \\
\hline TUC2 & 35.31 & 24.04 & 550 \\
\hline ANKR & 39.53 & 32.45 & 630 \\
\hline MATE & 40.38 & 16.42 & 755 \\
\hline NICO & 35.08 & 33.23 & 895 \\
\hline NOT1 & 36.52 & 14.59 & 1000 \\
\hline GRAZ & 47.04 & 15.29 & 1150 \\
\hline GLSV & 50.36 & 30.5 & 1170 \\
\hline LAMP & 35.5 & 12.61 & 1260 \\
\hline ZECK & 43.79 & 41.57 & 1375 \\
\hline & & & \\
\hline
\end{tabular}

epicenter of the main shock (red star). The closest to epicenter GNSS station is the 018B which located at the island of Samothraki. It's found only $16 \mathrm{~km}$ away. So, under this situation we can consider this station as EQ epicenter.

Figures $4 \mathrm{a}-\mathrm{d}$ display the TEC values variations for all stations during the study period. Graphs for each GNSS station are ordered by their distance from epicenter. As it shows, TEC values decrease 1-2 days prior the earthquake. Remarkable decrease in electron density is also observed at epicenter station (018B). This behavior could be related with the seismic event and would be further analyzed at next paragraphs.

\section{Validation with global models}

In order to evaluate our results, we compare the estimated TEC values series with those derived from CODE (Center of Orbit Determination in Europe) and JPL institute utilizing the associated produced IONEX files (Schaer, 1999). At CODE, the vertical TEC is modeled with a spherical harmonic expansion up to 15 degree and order 15 referring to a solar-geomagnetic reference frame. The produced ionospheric product (like maps) is regarded as one of the most precise TEC information. 


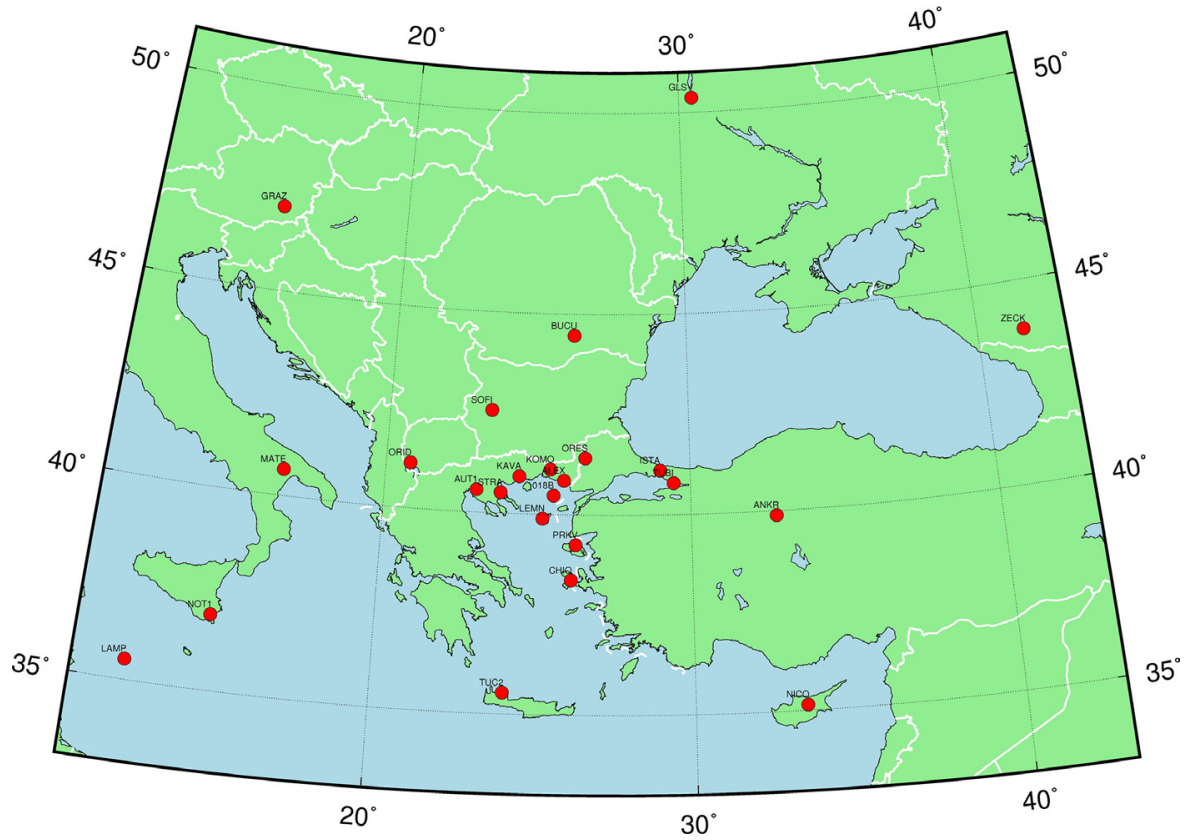

Figure 2. Geographical distribution of the selected permanent GNSS stations (red bullets)

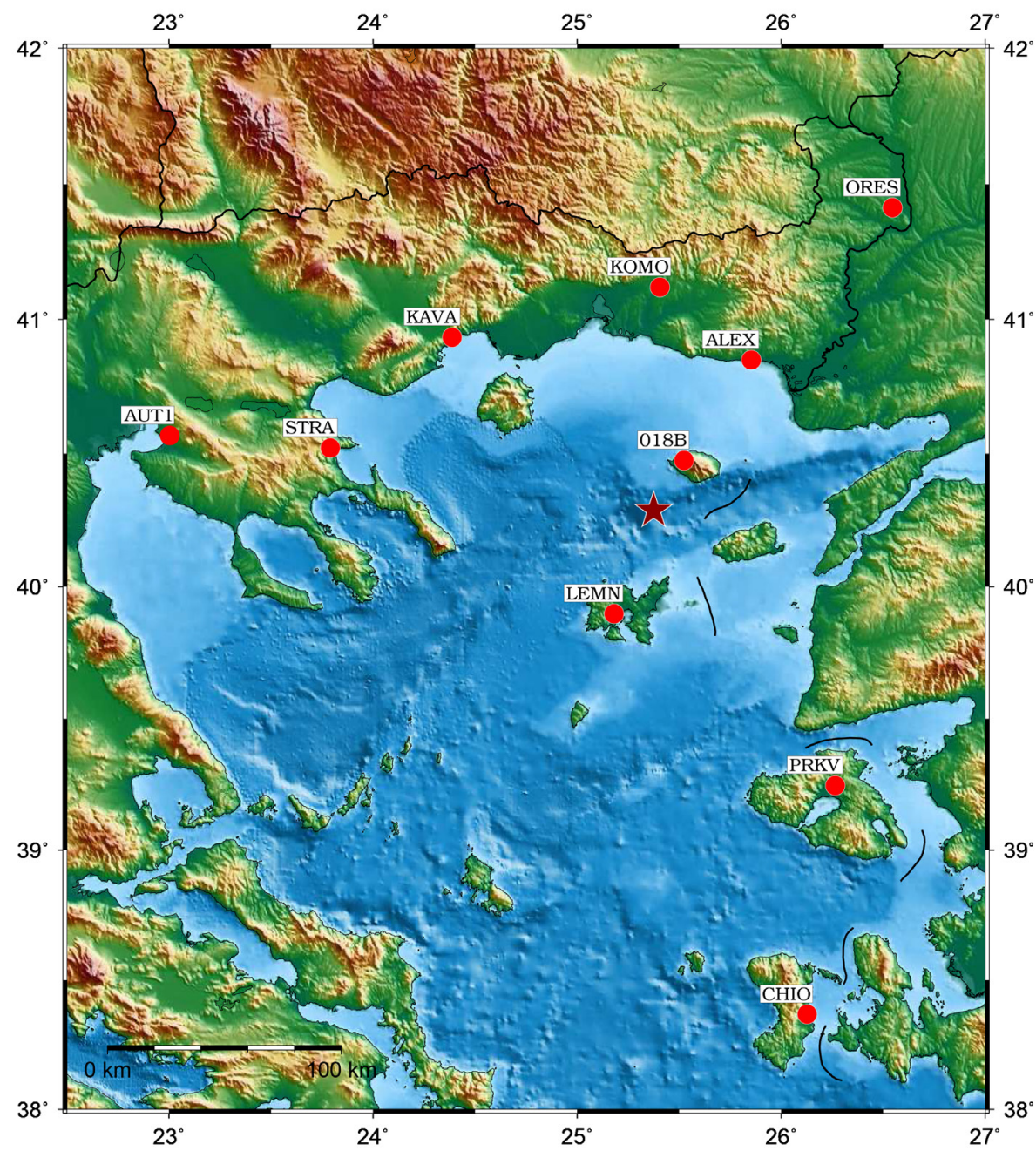

Figure 3. Geographical distribution of the Greek permanent GNSS stations (red bullets) and the EQ epicenter (red Star) 
a) $\begin{array}{rrrrrrrrrrrrrr}00 & 12 & 00 & 12 & 00 & 12 & 00 & 12 & 00 & 12 & 00 & 12 & 00 & 12\end{array}$

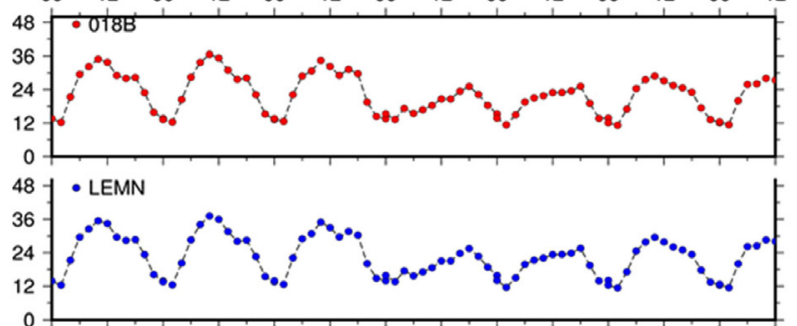

ALEX
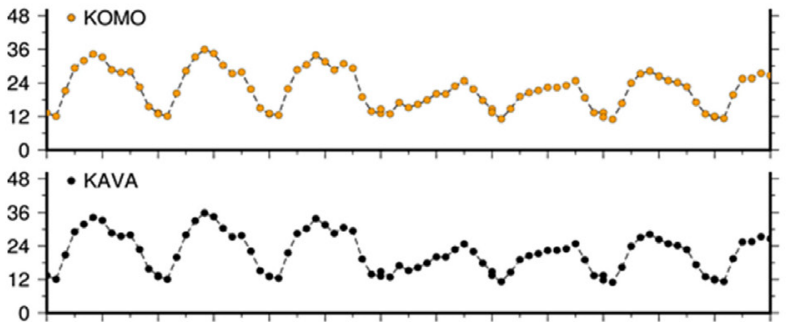

24 - PRKV

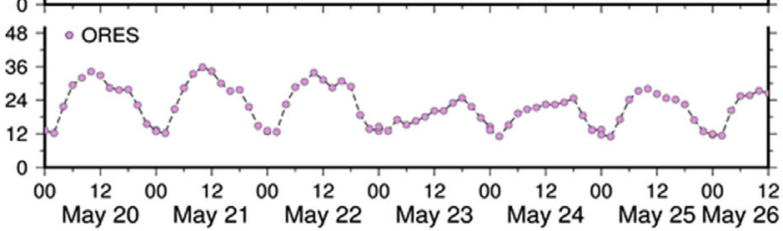

c)

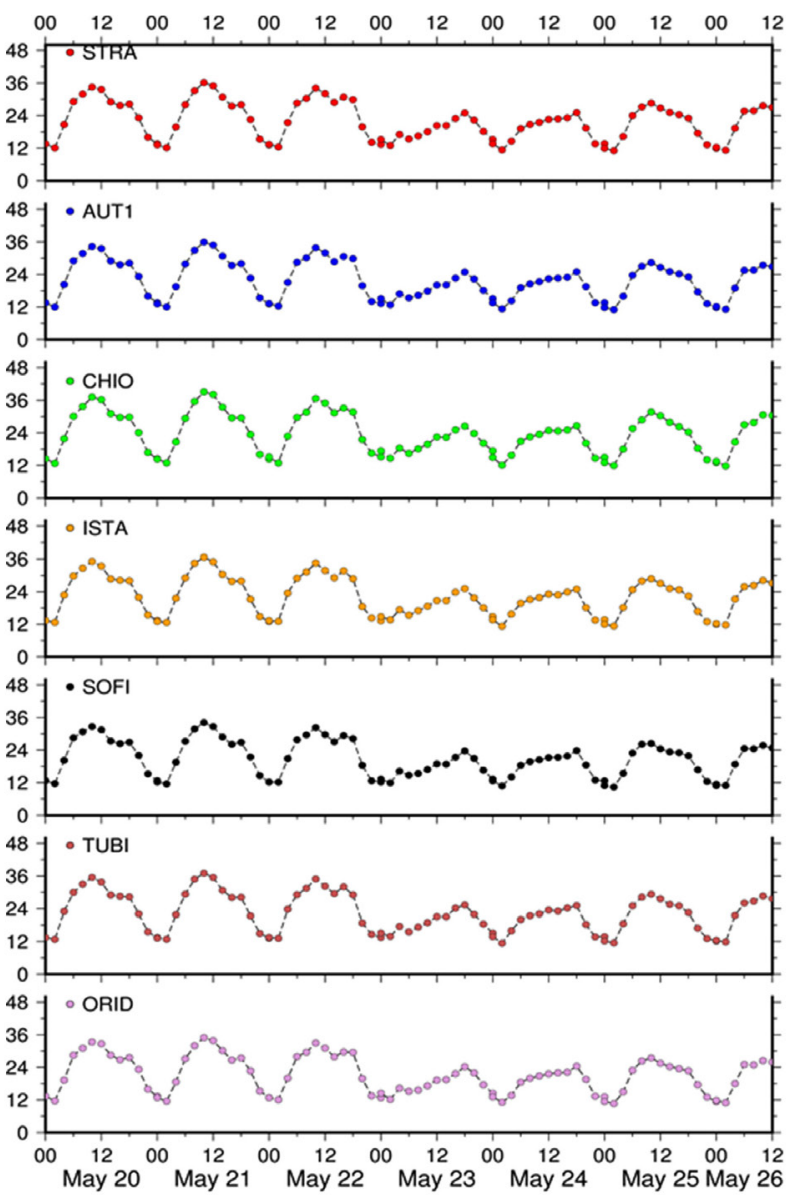

b) $\quad \begin{array}{llllllllllllll}00 & 12 & 00 & 12 & 00 & 12 & 00 & 12 & 00 & 12 & 00 & 12 & 00 & 12\end{array}$
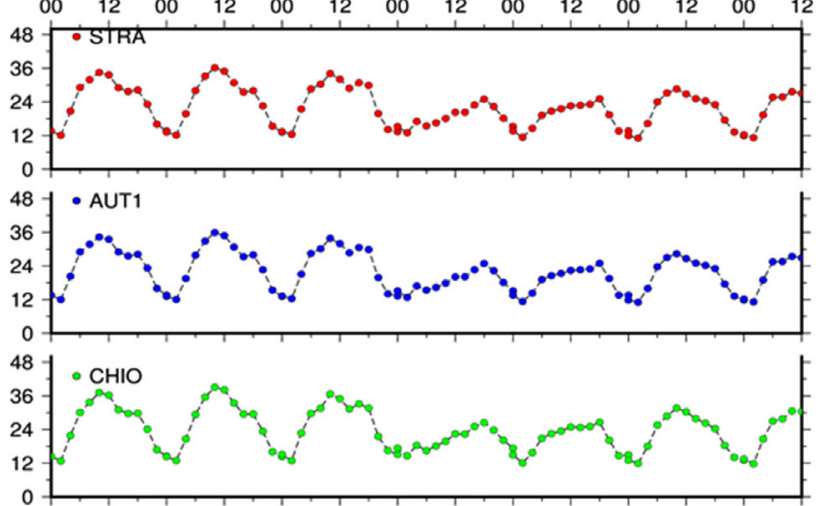

248 12. ISTA
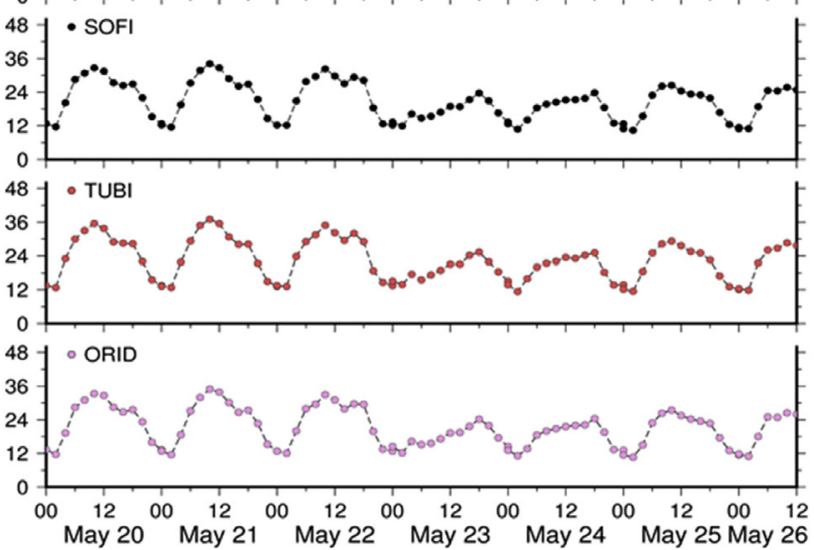

d)
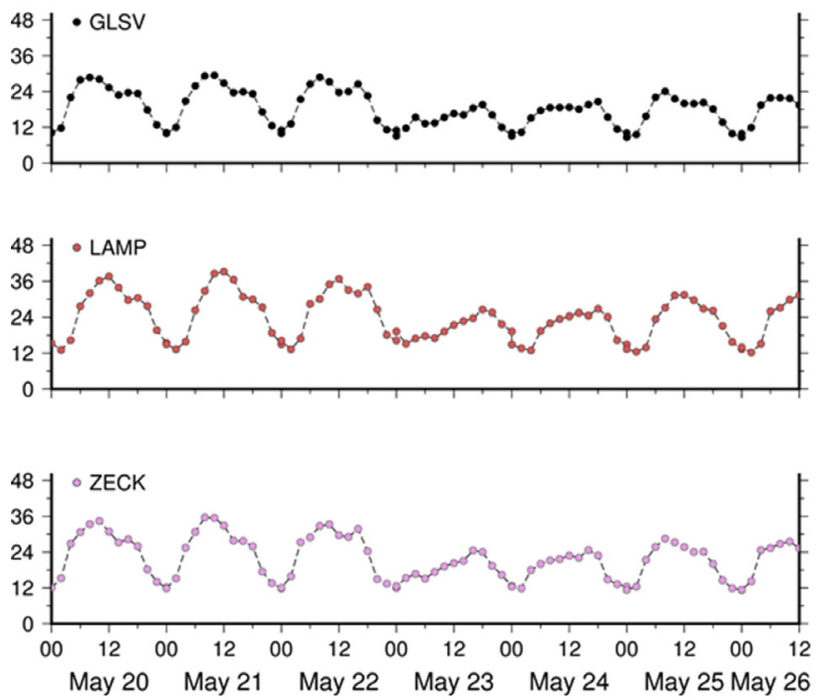

Figure 4. Diurnal TEC values in one-hour resolution for GNSS permanent stations during test period 
At JPL, since many years ago, ionosphere vertical total electron content (TEC) maps and daily GPS satellite differential code bias (DCB) values derived from the dualfrequency GPS data are provided to the scientific community. These ionosphere products are available in rapid solutions (less than 24 hours) and final solutions with a latency of approximately 11 days. At Figure 5, red line represents the JPL solution while black and blue lines are CODE and our PPP estimations respectively, for three selected GNSS stations. Table 2 presents, for station $018 \mathrm{~B}$, the basic statistical information of TEC differences (in TECu, where $1 \mathrm{TECu}=1016$ electrons $/ \mathrm{m}^{2}$ ) as they computed between current process and global ionospheric models.

Table 2. Statistical information for TEC differences between the various solutions (in TECu) for station $018 \mathrm{~B}$

\begin{tabular}{|l|c|c|}
\hline Basic statistical info & PPP - CODE & PPP - JPL \\
\hline Min & -9.4 & -9.4 \\
\hline Max & -1.2 & -2.5 \\
\hline Std. & 1.5 & 1.4 \\
\hline Mean Average & -4.8 & -6.4 \\
\hline
\end{tabular}

As it is clearly shown a bias between the different processing strategies exist. This result is hold for all of the selected stations. The critical conclusion which provided is that the decrease of TEC values before the seismic event (same signature) is also confirmed using this external information. Therefore, this values change is really holds 1-day prior the EQ and requires further investigation.

\section{TEC estimation using the NTCM-GL model}

During last year's, a new empirical model that allows determine global TEC very easily was proposed by Deutches Zentrum fur Luft-und Raumfahrt (DLR) (Jakowski, Hoque, \& Mayer, 2011). The Global Neustrelitz TEC Model (NTCM-GL) estimates TEC depending on geophysical parameters such as the geographic location, time and solar activity. It is comparable to the standard GPS model (Klobuchar, 1987) but with a higher accuracy. Therefore, we developed the proposed algorithm in a C++ programming language in order to estimate with the same time interval TEC values of our selected GNSS stations for the test period.

Figure 6 depicts the TEC variations as they derived from NTCM-GL model for a number of selected stations (018B, TUC2, NICO, ZECK). It is worth to be mentioned that similar behavior variation was also observed for all stations. As it is shown in Figure 6 the standard model it can't detect the previous TEC values variations (1-day prior the EQ) which found through global ionospheric models and PPP technique. This means that the used geophysical parameters (geographic location, time, solar activity) for the computation of ionospheric disturbance, don't play an important role. Therefore, this result enforces our interest for the relation of TEC decrement with an external source like the seismic events. In order to validate the non-important role of ionospheric standard parameters, we retrieved the geomagnetic and solar activity indices as they described at next section.

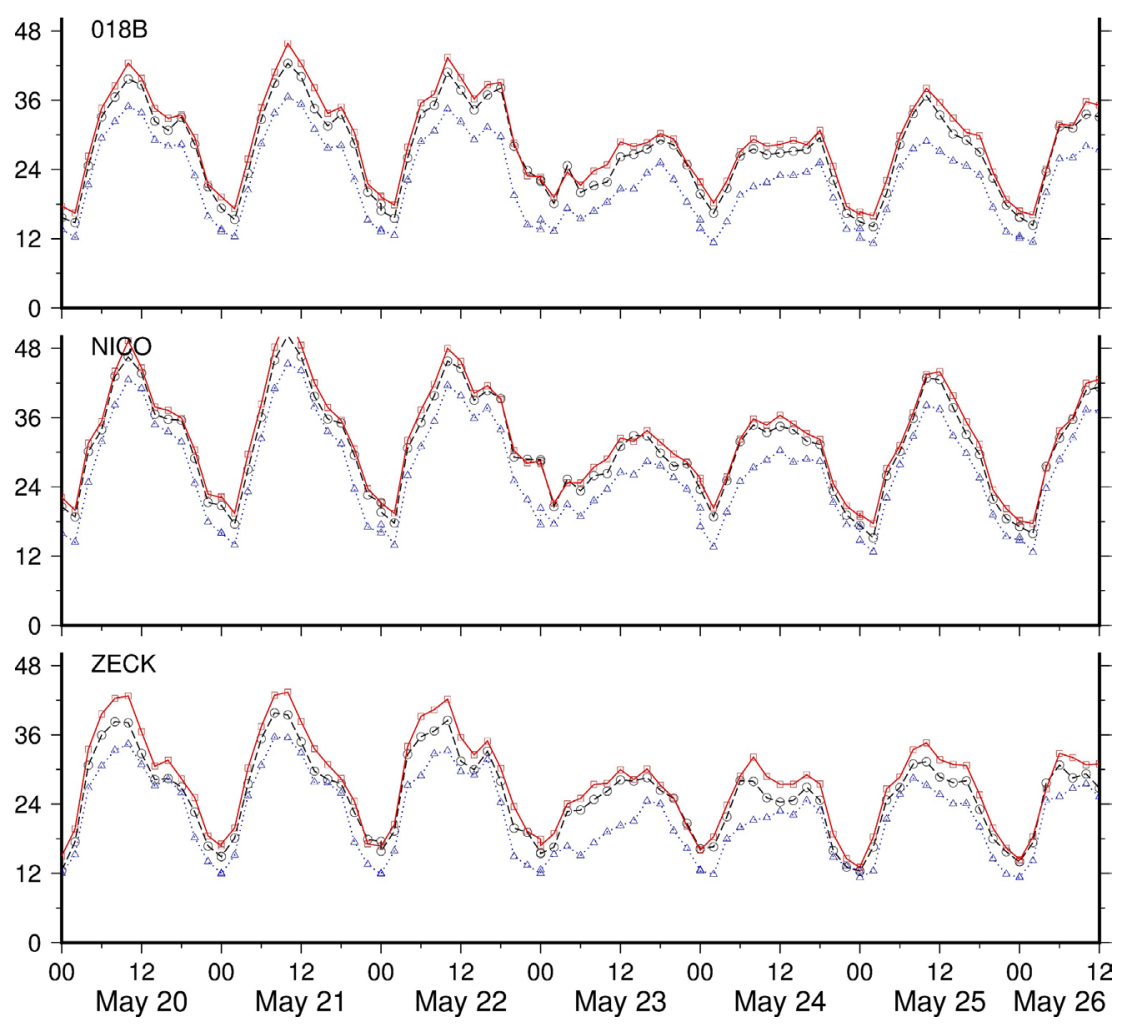

Figure 5. TEC values estimations using PPP solution and IONEX files from CODE and JPL 


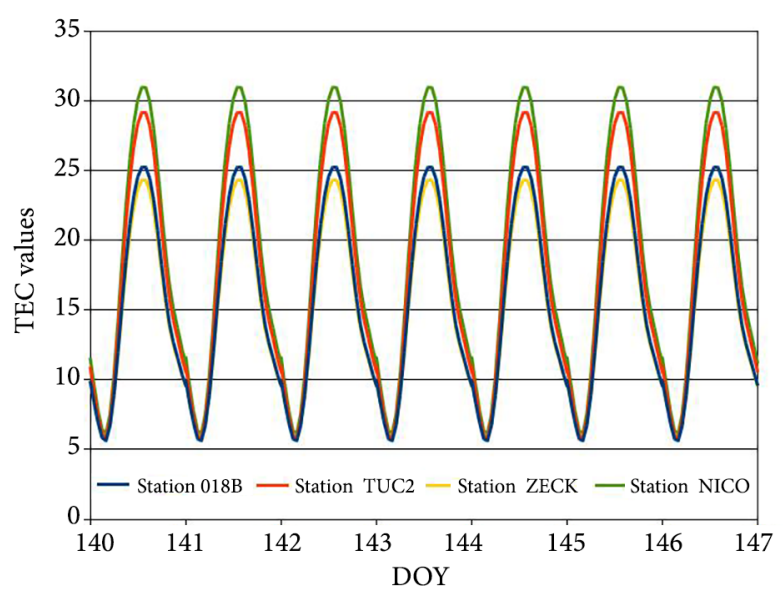

Figure 6. TEC values estimations using NTCM-GL model for the test period

\section{Geomagnetic data}

As it is known the ionospheric parameters are affected by solar geophysical conditions and geomagnetic storms with maximum impact in the equatorial and polar zones. The solar-terrestrial disturbances produce significant geomagnetic field disturbances. In order to distinguish the seismo-ionospheric perturbations from geomagnetic disturbances, the geomagnetic indice Dst have been checked from the Space Magnetism Faculty of Science at Kyoto university (http://swdcwww.kugi.kyoto-u.ac.jp/index.html). In addition, the Kp index monitors the planetary activity on a worldwide scale while the Dst index records the equatorial ring current variations. The relevant values were quoted from the NOAA in Boulder-Colorado (http://www. swpc.noaa.gov/products/planetary-k-index). A Dst of -50 or deeper indicates a geomagnetic storm-level disturbance. From the relevant figure (Figure 7) which displays the whole month, it can be seen that geomagnetic and planetary conditions are almost quite for the event day.

\section{TEC analysis}

In this section, the purpose of our study is to analyze and identify possible ionospheric anomalies preceding the strong earthquake at Samothraki island of North Aegean Sea in 2014 and describe main features through TEC values estimation obtained from GNSS permanent station data. Till now in various studies it has been reported that ionospheric precursors are observed between several days or even few hours prior to the earthquake and that earthquakes should exceed the magnitude of 5 Richter in order to provoke ionospheric variations-disturbances (Pulinets \& Legen'ka, 2002; Ondoh, 2008). Therefore, our study event can be found suitable for this investigation. More specific, most of our GNSS stations are within the earthquake preparation area. According to Dobrovolsky, Zubkov, and Myachkin (1979), the affected area is computed using the formula $R=100.43 \mathrm{M}$ where $R$ is the radius of the earthquake zone and $\mathrm{M}$ is the earthquake magnitude. In the case of Samothraki earthquake, the anomalous area is estimated as $926 \mathrm{~km}$. According to literature, plenty of studies have been successfully performed using statistical TEC analysis, while others, employed spectral or wavelet analysis, in order to relate the TEC disturbances with the seismic events.

In this study, a slightly different approach of differential TEC on our estimates were performed. Using this computational technique, we can (primary) handle better the TEC values estimations of each station and also to eliminate inter-frequency and other sources biases.

Therefore, in our case the sample TEC data (of each station) is transformed to input data TECi according to the following simple formula (linear scaling):

$$
T E C_{i}=2 \frac{T E C_{i}-T E C_{\min }}{T E C_{\max }-T E C_{\min }}-1,
$$

where, the values of TECmin and TECmax refers to maximum and minimum of the test period. TECi is the

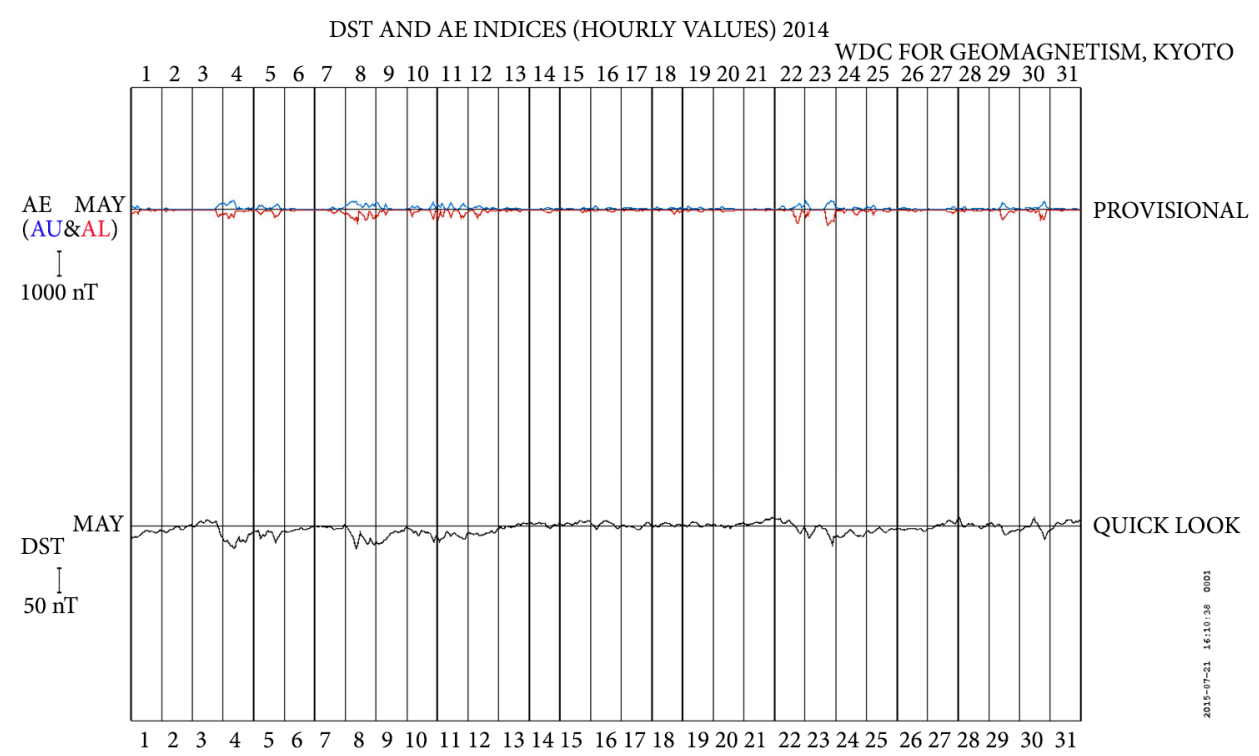

Figure 7. D-st and AE (Auroral Electrojet) indices variations in May of 2014 
so-called value range. As a consequence, in our further analysis the normalized TEC values were used.

Since ionospheric TEC anomalies could be provoked not only from earthquakes but from other sources as well, we performed the spatial distribution of ionospheric conditions during test period in order to isolate the (probable) seismically induced TEC variations before the Samothraki earthquake. Figure 8 illustrate the differences of normalized TEC values between the first day (DOY 140, quiet day) and all the following days for the maximum solar activity time period (14:00 local time). Each snapshot covers the preparation zone and the all the distances from EQ epicenter. As it clearly shown, the maximum differences appear between DOY 143 (snapshot c) one-day prior the seismic event and all broader area was affected by this TEC disturbance. In addition, higher differences were founded at stations with lower latitudes such as, MATE, TUC2, NICO but this result is in general expected, due to these stations are closer (than the others) to the equatorial ionospheric zone.

Based on most previous studies ionospheric precursors appear 1-5 days before the impending earthquake, nevertheless, in the case of strong earthquakes ionospheric anomalies can be detected up to 12 days before as well (Pulinets \& Boyarchuk, 2004). Focusing on DOY 143 and due to the fact that TEC decrease was also observed at

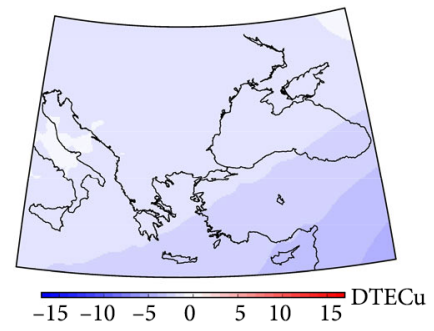

a)

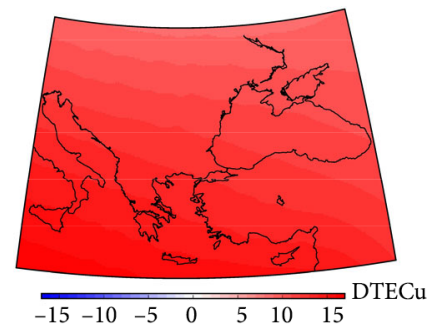

c)

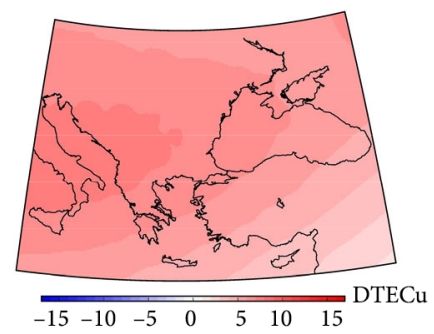

e) stations outside the preparation zone, we search the occurrence of maximum variability (peak values) in twelve intervals at two hours, for each GNSS station. This analysis shown that the most appearances was found at station NICO in Cyprus (4 times within the day) and then at stations MATE and LAMP in Italy and TUC2 in Crete Island-Greece. While, two times founded at ZECK (Russia) and one appearance founded at GRAZ (Austria) and GSLV (Ukraine) respectively.

Study in detail this result, we decided to design the common areas that generated between circles with radius of $926 \mathrm{~km}$ and center each of the candidate's station. But, the only restriction that we applied was to keep the candidate station within the preparation zone from EQ epicenter. This geometric approach shown that common area, keeping always as basic circle that which derived from NICO station, generated only through the combination with MATE and TUC2 stations. On Figure 9 the sketched area is extracted as the common area between the three circles intersection. This region includes the EQ epicenter and several other local geodynamical areas.

More specific, according to GreDaSS database (Caputo et al., 2013), this area includes the North Aegean Sea which dominated by two regional tectonic structures. The North Aegean Basin and North Aegean Trough, which are directly connected and represented the western

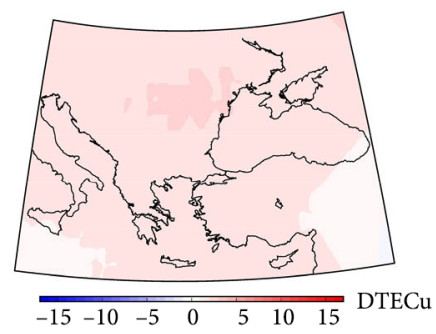

b)

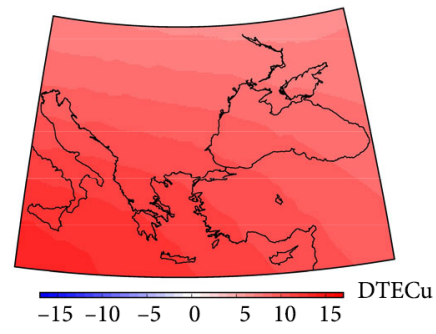

d)

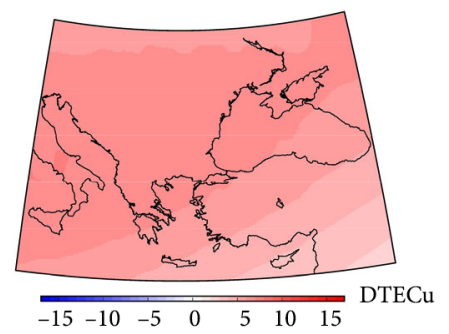

f)

Figure 8. Snapshots of TEC differences between first day (DOY 140) and all the others of the test period 


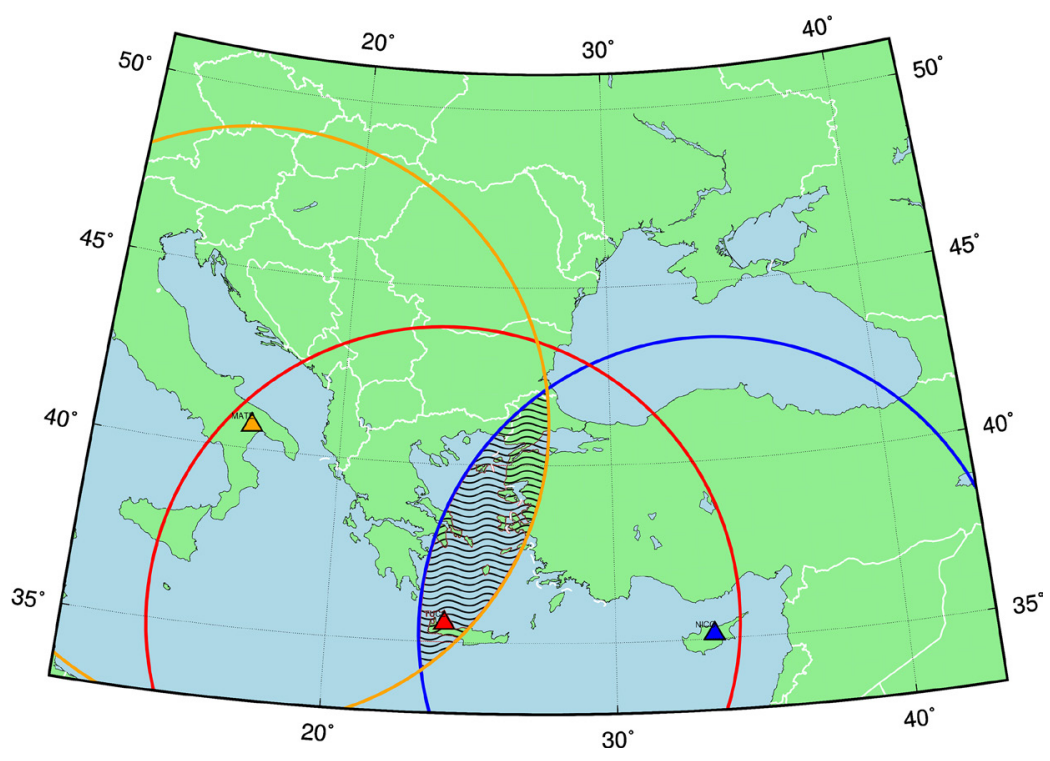

Figure 9. Common area (sketched) generated through three circles intersection with radius of $926 \mathrm{Km}$. Color triangles represent each circle center

continuation of the North Anatolian Fault which characterized as major seismogenic source. Moreover, in the North Aegean region, there are other active tectonic structures or kinematically associated with those of the North Aegean Basin and North Aegean Trough like the Samothraki individual seismogenic source. As a consequence, our approach suggests an admissible connection of TEC variation with the $\mathrm{EQ}$ event.

In addition, the combination of the lithosphere-atmosphere-ionosphere coupling (LAIC) mechanism through acoustic or gravity waves with area specific geophysical characteristics might be found a useful contribution on several TEC variation studies as precursory point region for seismic events.

\section{Conclusions}

In this paper, we have examined TEC changes over 24 permanent GNSS stations around the Samothraki earthquake occurred on 24 May 2014. All of the selected stations cover an area size of about $1700 \mathrm{~km}$ in latitude and $2600 \mathrm{~km}$ in longitude. Ionospheric TEC decrease 1-day prior could be related to the impending event. This result can be obvious when a dedicated data processing scenario utilizes research-type oriented software, like Bernese GPS software, is performed. In contrast, the use of standardempirical models for TEC values monitoring in such cases shows that they cannot provide this capability.

It was found obvious, thus, specific spatial analysis on TEC values estimated from permanent GNSS networks is an effective tool for the investigation of ionospheric variations preceding large earthquakes. Finally, the combination of the lithosphere-atmosphere-ionosphere coupling (LAIC) mechanism with area specific geophysical characteristics has an important role and may point the location area of the Earthquake. For that reason, is highly suggested for future ionospheric earthquake-related studies.

\section{Acknowledgements}

The authors would like to thank HxGN/SmartNet-Greece and HEPOS networks for providing the GNSS data. Figures in this paper were plotted with the public domain Generic Mapping Tools (GMT) software (Wessel, Smith, Scharroo, Luis, \& Wobbe, 2013). The authors C.P. S.B. and I.K. acknowledges partial support of this work by the project "HELPOS - Hellenic System for Lithosphere Monitoring" (MIS 5002697) which is implemented under the Action "Reinforcement of the Research and Innovation Infrastructure", funded by the Operational Programme "Competitiveness, Entrepreneurship and Innovation" (NSRF 2014-2020) and co-financed by Greece and the European Union (European Regional Development Fund).

\section{References}

Astafyeva, E., \& Heki, K. (2011). Vertical TEC over seismically active region during low solar activity. Journal of Atmospheric and Solar-Terrestrial Physics, 73(13), 1643-1652.

https://doi.org/10.1016/j.jastp.2011.02.020

Bitharis, S., Fotiou, A., Pikridas, C., Rossikopoulos, D., Pavlides, S., \& Chatzipetros, A. (2016). The Samothrace earthquake of May 2014 and the displacements estimations using permanent GPS stations data. Bulletin of the Geological Society of Greece, 50(3), 1545-1552. http://doi.org/10.12681/bgsg.11867

Boehm, J., Werl, B., \& Schuh, H. (2006). Troposphere mapping functions for GPS and very long baseline interferometry from European Centre for Medium-Range Weather Forecasts operational analysis data. Journal of Geophysical Research, 111, B02406. https://doi.org/10.1029/2005JB003629 
Calais, E., \& Minster, J. B. (1998). GPS, earthquakes, the ionosphere, and the space shuttle. Physics of the Earth and Planetary Interiors, 105(3-4), 167-181.

https://doi.org/10.1016/S0031-9201(97)00089-7

Caputo, R., Chatzipetros, A., Pavlides, S., \& Sboras, S. (2013). The Greek Database of Seismogenic Sources (GreDaSS): state-of-the-art for northern Greece. Annals of Geophysics, 55(5), 859-894.

Contadakis, M. E., Arabelos, D., Asteriadis, G., Spatalas, S. D., \& Pikridas, C. (2008). TEC variations over the Mediteranean during the seismic activity period of the last quarter of 2005 in the area of Greece. Natural Hazards and Earth System Sciences, 8, 1267-1276. https://doi.org/10.5194/nhess-8-1267-2008

Contadakis, M. E., Arabelos, D., Asteriadis, G., Pikridas, C., \& Spatalas, S. D. (2012). Total electron content variations over southern Europe before and during the M 6.3 Abruzzo earthquake of April 6, 2009. Annals of Geophysics, 55(1), 83-93.

Dach, R., \& Walser, P. (2015). Tutorial of Bernese GNSS software version 5.2. AIUB, Bern, Switzerland.

Dobrovolsky, I. R., Zubkov, S. I., \& Myachkin,V. I. (1979). Estimation of the size of earthquake preparation zones. Pure and Applied Geophysics, 117(5), 1025-1044.

https://doi.org/10.1007/BF00876083

Jakowski, N., Hoque, M. M., \& Mayer, M. (2011). A new global TEC model for estimating transionospheric radio wave propagation errors. Journal of Geodesy, 85, 695-974.

https://doi.org/10.1007/s00190-011-0455-1

Jolivet, L. (2011). A comparison of geodetic and finite strain in the Aegean, geodynamic implications. Earth Planetary Science Letters, 187, 95-104. https://doi.org/10.1016/S0012-821X(01)00277-1

Koperanov, V., Hayakawa, M., Yampolski, Y., \& Lizunov, G. (2008). AGW as a seismo-ionospheric responsible agent. Physics and Chemistry of the Earth, Parts A/B/C, 34(6-7), 485495. https://doi.org/10.1016/j.pce.2008.07.014

Klobuchar, J. (1987). Ionospheric time delay algorithm for single frequency GPS users. In IEEE Transactions on Aerospace and Electronic Systems, 23, 325-332.

https://doi.org/10.1109/TAES.1987.310829

Liu, J. Y., Chuo, Y. J., Shan, S. J., Tsai, Y. B., Chen, Y. I., Pulinets, S. A., \& Yu, S. B. (2004). Pre-earthquake ionospheric anomalies registered by continuous GPS TEC measurements. Annals of Geophysics, 22, 1585-1593.

https://doi.org/10.5194/angeo-22-1585-2004

Molchanov, O., Biagi, P. F., Hayakawa, M., Lutikov, A., Yunga, S., Iudin, D., Andreevsky, S., Rozhnol, A., Surkov, V., Chebrov, V., Gordeev, E., Schekotov, A., \& Fedorov, E. (2004). Lithosphere-atmosphere-Ionsphere coupling as governing mechanism for preseismic short-term events in atmosphere and ionosphere. Natural Hazards and Earth System Science, 4(5/6), 757-767. https://doi.org/10.5194/nhess-4-757-2004

Molchanov, O., Schekotov, A., Solovieva, M., Fedorov, E., Gladyshev, V., Gordeev, E., Chebrov, V., Saltykov, D., Sinitsin, V. I., Hattori, K., \& Hayakawa, M. (2005). Near seismic effects in ULF fields and seismo-acoustic emission: statistics and explanation. Natural Hazards and Earth System Science, 5, 1-10. https://doi.org/10.5194/nhess-5-1-2005

Ondoh, T. (2008). Investigation of precursory phenomena in the ionosphere, atmosphere and groundwater before large earthquakes of M.6.5. Advances in Space Research, 43, 214-233. https://doi.org/10.1016/j.asr.2008.04.003
Papazachos, C., Kiratzi, A., \& Kontopoulou, D. (1998). Active tectonics in Aegean and surrounding area. In Basic results of the seismologic in Greece in Honorem Prof. B .C. Papazachos (pp. 49-74). Thessaloniki: Ziti editions (in Greek).

Pavlides, S., Caputo, R., Sboras, S., Chatzipetros, A., Papathanasiou, G. \& Valkaniotis, S. (2010). The Greek catalogue of active faults and database of seismogenic sources. Bulletin of the Geological Society of Greece, 43(1), 486-494.

https://doi.org/10.12681/bgsg.11199

Pikridas, C., \& Chatzinikos, M. (2007). TEC values estimation over a permanent GPS station. Coordinates, 3(4), 22-24.

Pulinets, S., \& Legen'ka, A. (2002). Dynamics of the near-equatorial ionosphere prior to strong earthquakes. Geomagnetism and Aeronomy, 42, 239-244.

Pulinets, S., Legen, A. D., Gaivoronskaya, T. V., \& Depuev, V. K. (2003). Main phenomenological features of ionospheric precursors of strong earthquakes. Journal of Atmospheric and Solar-Terrestrial Physics, 65(16-18), 1337-1347. https://doi.org/10.1016/j.jastp.2003.07.011

Pulinets, S., \& Boyarchuk, K. (2004). Ionospheric precursors of earthquakes. Berlin: Springer.

Saastamoinen, J. (1972). Atmospheric correction for the troposphere and stratosphere in radio ranging of satellites. In S. W. Henriksen, A. Mancini, \& B. H. Chovitz (Eds.), The use of artificial satellites for geodesy, geophysics monograph series (Vol. 15, pp. 247-251). AGU, Washington D.C. https://doi.org/10.1029/GM015p0247

Sboras, S., Chatzipetros, C., Pavlides, P., Pikridas, C., Fotiou, A., \& Bitharis, S. (2015, April). The May 24, 2014 North Aegean Trough earthquake: stress change and displacement patterns. Paper presented at 6 th International INQUA Meeting on Paleoseismology, Active Tectonics and Archaeoseismology, Pescina, Italy.

Schaer, S. (1999). Mapping and predicting the Earth's ionosphere using the global positioning system ( $\mathrm{PhD}$ thesis). University of Bern, Switzerland.

Sharma, K., Dabas, R. S., Sarkar, S. K., Das, R. M., Ravindran Sudha, Gwal, A. K. (2010). Anomalous enhancement of ionospheric F2 layer critical frequency and total electron content over low latitudes before three recent major earthquakes in China. Journal of Geophysical Reseach, 115, A11313. https://doi.org/10.1029/2009JA014842

Singh, O. P., Chauhan, V., Singh, V., \& Singh, B. (2009). Anomalous variation in total electron content (TEC) associated with earthquakes in India during September 2006 - November 2007. Physics and Chemistry of the Earth, Parts A/B/C, 34(67), 479-484. https://doi.org/10.1016/j.pce.2008.07.012

Wessel, P., Smith, W. H. F., Scharroo, R., Luis, J., \& Wobbe, F. (2013). Generic mapping tools: Improved version released. Eos, Transactions, American Geophysical Union, 94(45), 409410. https://doi.org/10.1002/2013EO450001

Wild, U. (1994). Ionosphere and geodetic satellite systems: Permanent GPS tracking data for modeling and monitoring. In Geodatisch-geophysikalische Arbeiten in der Schweiz (Vol. 48). Schweizerische Geodätische Kommission.

Yao, Y., Chen, P., Wu, H., Zhang S., \& Peng, W. (2012). Analysis of ionospheric anomalies before the $2011 \mathrm{Mw} 9.0$ Japan earthquake. Chinese Science Bulletin, 57(5), 500. https://doi.org/10.1007/s11434-011-4851-y 